\title{
Hydroxyapatite Particles Induced Modulation of Collagen Expression and Secretion in Primary Human Dermal Fibroblasts
}

This article was published in the following Dove Press journal: International Journal of Nanomedicine

\author{
Moumita Rakshit ${ }^{1}$ \\ Archana Gautam' \\ Li Zhen Toh ${ }^{2}$ \\ Ying Shi Lee ${ }^{2}$ \\ Hui Ying Lai ${ }^{1}$ \\ Tina T Wong ${ }^{1,2}$ \\ Kee Woei $\mathrm{Ng}$ (D) $^{1,3-5}$ \\ 'School of Materials Science and \\ Engineering, Nanyang Technological \\ University, Singapore 639798, Singapore; \\ ${ }^{2}$ Ocular Therapeutics and Drug Delivery, \\ Singapore Eye Research Institute, \\ Singapore 169856, Singapore; \\ ${ }^{3}$ Environmental Chemistry and Materials \\ Centre, Nanyang Environment \& Water \\ Research Institute, Singapore 637/4I, \\ Singapore; ${ }^{4}$ Skin Research Institute of \\ Singapore, Singapore 138648, Singapore; \\ ${ }^{5}$ Center for Nanotechnology and \\ Nanotoxicology, Harvard T.H. Chan \\ School of Public Health, Cambridge, MA \\ 02115 , USA
}

Correspondence: Tina T Wong; Kee Woei $\mathrm{Ng}$

Tel +656322 83I3; +65 65I38294

Email tina.wong.t.l@singhealth.com.sg;

kwng@ntu.edu.sg
Background: Hydroxyapatite (HA) $\left[\mathrm{Ca}_{5}(\mathrm{PO} 4)_{3}(\mathrm{OH})\right]$ is a naturally occurring calcium phosphate which makes up $60-70 \%$ of the dry weight of human bones. Nano-scale HA particles are increasingly being used as carriers for controlled and targeted delivery of bioactive agents like drugs, proteins, and nucleic acids due to their high porosity, negative charge, and biodegradability.

Purpose: Although much effort has been devoted to understanding the delivery kinetics and effects of the payloads in such carriers, a thorough understanding of the influence of the carriers themselves is lacking.

Methods: HA particles $(300 \mu \mathrm{g} / \mathrm{mL})$ were administered to primary human dermal fibroblasts (HDFs). The uptake and intracellular localization of the particles were determined by flow cytometry, confocal imaging, and transmission electron microscopy (TEM). Immunological assays and PCR were performed to determine the levels of proinflammatory cytokines and collagens in cell lysates and media supernatant.

Results: The current study explores the effects of poly-dispersed HA particles on primary HDFs as a model system. The majority of the particles were determined to range between 150 and $200 \mathrm{~nm}$ in diameter. Upon exposure to HA suspensions, primary HDFs internalized the particles by endocytosis within 6 hours of exposure, showing maximum uptake at 72 hours following which the particles were exocytosed by 168 hours. This correlated to reduced secretion of various pro-inflammatory and pro-collagenic cytokines. Biochemical analysis further revealed a reduction in Type I collagen expression and secretion.

Conclusion: HA particles have an immune-modulatory effect on dermal fibroblasts and reduce collagen production, which may impact the integrity of the extracellular matrix (ECM). This study demonstrates the need to consider the secondary effects of particulate carriers like HA, beyond basic cytotoxicity, in the specific tissue environment where the intended function is to be realized.

Keywords: carrier particles, collagen expression, extracellular matrix, time-weighted average exposure

\section{Introduction}

Recent times have seen extensive medical and biological applications of engineered particles, especially those in the nano-sized range $(<100 \mathrm{~nm})$, in various areas like drug delivery, gene delivery, catalysts, biosensors, tissue engineering, MRI contrast enhancement, phagokinetic studies, and fluorescent biological labels. ${ }^{1-3}$ Albanese et al have categorized carrier particles destined for biomedical applications into three generations based on the nano-bio interactions. The first generation comprises biocompatible 
particles with desirable surface properties aiding in quick uptake by bio-membranes. The second-generation particles are improvised with enhanced targeting by virtue of surface modifications such as antibody or poly-ethylene glycol (PEG) coating. The third-generation particles involve "intelligent" environment-responsive systems with improved and targeted compound delivery. ${ }^{4}$

Hydroxyapatite (HA) - a calcium phosphate compound and a major mineral component of bone and teeth, is a firstgeneration carrier particle which is highly explored for targeted drug or nucleic acid delivery. ${ }^{5,6}$ HA particles are a remarkable choice for therapeutic applications owing to their biocompatibility and biomimetic properties. Additionally, HA has been deemed the least soluble of all calcium phosphates known so far. ${ }^{1,7}$ A wide range of active agents can easily be loaded into HA particles through in situ or ex situ processes..$^{8-11}$ Various methods are employed to utilize HA as carriers for different compounds: 1) coating of HA surface with nanoparticles, 2) physical interaction with antibiotics, 3) physical interaction with anticancer drugs, 4) core shell magnetic HA, 5)noncovalent attachment and 6) covalent attachment of drugs. ${ }^{6}$

However, it is important to note the potential toxic effects of HA particles when exposed under physiological conditions. In addition to exposure as carriers, cells may also be exposed to HA particles in pathological conditions such as osteoarthritis, gout, and atherosclerosis where degeneration of the bones may result in ectopic deposition of these crystals. ${ }^{12-}$

${ }^{14}$ Furthermore, implanted prosthetics may also release HA particles which can trigger localized inflammation. ${ }^{14,15}$ HA crystals may be internalized by macrophages leading to nucleotide-binding oligomerization domain, leucine-rich repeat and pyrin domain 3 (NLRP3) triggered activation of crystal-induced IL-1 $\beta$ secretion. ${ }^{14,16}$ Adding to the toxicity, Sun et al have reported that the addition of HA particles to fibroblasts and myoblasts resulted in a significant reduction of TGF- $\beta$ levels, irrespective of particle size. ${ }^{17}$

Hence, to ensure safe clinical translation, the behavior of these particles in biological systems needs to be fully understood. To this end, it is pertinent to investigate the internalization, biostability, biopersistence, toxicity, and cell/tissue-specific physiological influences of the particles. The bioactivity of particles is affected by variations in their physicochemical properties. In the case of HA particles, it had been established that there is a direct relationship between their size, shape, and surface topography and their role in modulating the innate immune response. ${ }^{18-20}$ The current study thus aims to understand the potential secondary deleterious effects of prolonged exposure of a common human stroma cell type, primary dermal fibroblasts, to HA particles. Our findings revealed that exposure to HA particles results in adverse effects on pro-inflammatory cytokine release as well as suppression of Collagen 1 gene expression, cellular protein levels, and secretion by dermal fibroblasts.

\section{Materials and Methods \\ Particle Characterization}

Hydroxyapatite (HA) particles $(<200 \mathrm{~nm})$ were purchased from Sigma Aldrich (USA). Particle sizes were determined by transmission electron microscopy (TEM, Carl Zeiss Libra 120 Plus) with an accelerating voltage of $120 \mathrm{kV}$ and the average diameter of HA particles was calculated using ImageJ $(\mathrm{n}=500)$.

\section{Cell Culture}

Primary human dermal fibroblasts (HDFs) were purchased from American Type Culture Collection (ATCC). Primary human conjunctival fibroblasts (HCFs) were purchased from Lion's Eye Institute for Transplant and Research (Tampa, USA) and primary mouse conjunctival fibroblasts (MCFs) were harvested from the eyes of wild type C57BL6/ $\mathrm{J}$ mice $^{21}$ and received from the Singapore Eye Research Institute (SERI). All cells were cultured in Dulbecco's Modified Eagle's Medium (DMEM) (Gibco, USA) supplemented with $10 \%$ fetal bovine serum (FBS) and $1 \%$ penicillin-streptomycin (Pen-Strep) (both from Thermo Scientific HyClone, USA). Growth conditions were $37^{\circ}$ $\mathrm{C}$ with $5 \% \mathrm{CO}_{2}$ in a humidified environment.

\section{Treatment of Cells with Particles}

Various particles (HA, FITC-HA, $\mathrm{TiO}_{2}, \mathrm{SiO}_{2}$, or Ag) were suspended in $0.2 \mu \mathrm{m}$ filtered purified water (Millipore), sonicated and vortexed for $5 \mathrm{~min}$ and collected by centrifugation (ST16R, Sorvall) at $16,000 \mathrm{~g}$ for $1 \mathrm{~min}$. The procedure was repeated five times to wash the HA particles and a $40 \mathrm{mg} / \mathrm{mL}$ stock suspension was prepared in $0.1 \mathrm{M} \mathrm{NaCl}$ before administering to cells. HDFs were seeded in various cell culture formats and exposed to $300 \mu \mathrm{g} / \mathrm{mL}$ working solution in DMEM.

\section{Cell Proliferation Assay}

Cell proliferation was measured by real-time cell analyzer (xCELLigence RTCA Systems; ACEA Biosciences Inc., 
USA). Five hundred cells per well were seeded in 96-well E-Plates (E-Plates 96) in triplicates for different conditions and allowed to stabilize for 24 hours before exposure to 300 $\mu \mathrm{g} / \mathrm{mL}$ HA particles. After initial stabilization and attachment, the rate of cell proliferation was continuously monitored for a period of 7 days.

\section{Cytokine Array}

A total of 100,000 cells were seeded on $35 \mathrm{~mm}$ plates and exposed to $300 \mu \mathrm{g} / \mathrm{mL}$ HA working solution in $2 \mathrm{~mL}$ media. The supernatant was collected on day 3 and subjected to Human Inflammation Antibody Array (Abcam; USA) overnight. The kit protocol was followed for the subsequent steps.

\section{Transmission Electron Microscopy (TEM)}

To evaluate the localization of the HA particles inside the cellular organelles, TEM was carried out. Briefly, primary HDF cells were exposed to $300 \mu \mathrm{g} / \mathrm{mL}$ HA particles for 3 and 7 days. The cells were then trypsinized, collected, washed with phosphate buffer saline (PBS), and fixed with a mixture of $4 \%$ paraformaldehyde and $2 \%$ glutaraldehyde solution overnight at room temperature (RT). Further, the cells were post-fixed with $2 \%$ osmium tetraoxide (Sigma Aldrich, USA) for 1 hour and washed with PBS to remove the fixative. Dehydration of cells was done with an ascending series of ethanol $(25 \%, 50 \%, 75 \%$, $95 \%, 100 \%)$ and pure acetone $(100 \%)$ for $15 \mathrm{~min}$ each at RT. The cells were then infiltrated with a mixture of epoxy resin (Araldite 502 kit, Ted Pella, USA) and acetone at the ratio 1:1 for $30 \mathrm{~min}$ and 1:6 overnight. Each cell pellet was embedded in fresh resin within a polyurethane mold and polymerized for 48 hours at $60^{\circ} \mathrm{C}$. The resulting resinembedded cell capsules were sectioned at a thickness of 80-100 nm with an ultramicrotome and collected on copper grids (EMS). The sections were stained with $2 \%$ uranyl acetate for $8 \mathrm{~min}$ and lead citrate for $1 \mathrm{~min}$ before imaging (TEM, Carl Zeiss Libra 120 Plus).

\section{Flow Cytometry}

HDFs were untreated (blank) or exposed to $300 \mu \mathrm{g} / \mathrm{mL}$ of FITC-tagged HA particles for 6, 12, 24 (day 1), 72 (day 3), 120 (day 5) and 168 (day 7) hours. Cells were washed, trypsinized, and collected after each time point and subjected to trypan blue (Sigma, USA) exclusion to determine cell viability. The cells were resuspended in PBS and fed through the Guava easyCyte HT 2-laser flow cytometer (Millipore, USA) with excitation by the blue $(488 \mathrm{~nm})$ laser and the gain controls at their default settings (yellow and green fluorescence). Triplicate samples were evaluated for both blank and the FITC-HA particle-exposed cells. Approximately 1000 cells were analyzed for each sample.

\section{ELISA}

A total of 100,000 cells were seeded in $35 \mathrm{~mm}$ plates and exposed to $300 \mu \mathrm{g} / \mathrm{mL}$ HA working solution in $2 \mathrm{~mL}$ media. Supernatants were collected on day 3 and analyzed using the Human Collagen Type I colorimetric ELISA Kit (Novus; USA) overnight. The kit protocol was followed for the subsequent steps.

\section{Reverse Transcription (RT-PCR) and Quantitative Real-Time PCR (qPCR)}

RT-PCR followed by qPCR was performed to examine the expression levels of Collagen 1 in untreated controls (CTR) and HA particle exposed primary HDF cells. Total RNA was extracted using the PureLink RNA Mini Kit (Ambion, Thermo Fisher Scientific, USA) following the manufacturer's instructions, and stored at $-80^{\circ} \mathrm{C}$ until use. Total RNA was subjected to DNase treatment and cDNA was synthesized from $2 \mu \mathrm{g}$ of the total RNA with the SuperScript IV Vilo Master Mix with ezDNase Enzyme (Thermo Fisher Scientific, USA). The resultant cDNA was used for qPCR analysis of gene expression. 90-180 bp regions of human actin,coll $\alpha 1$, col3 and col5 were amplified with specific primers (coll 5'-TCTGCGACAACGGCAAG GTG-3'，5'-GACGCCGGTGGTTTCTTGGT-3'; col3，5'ACACGTTTGGTTTGGAGAGTCC-3', 5'-CTGCACA TCAAGGACATCTTCAG-3'; cols, 5'-GCGTGGGAA ACTGACCAAGA-3'， GTGACGCTTCACCGAAGTCA, and actin, 5'-CCAGAGGCGTACAGGGATAG-3', 5'CCAACCGCGAGAAGATGA-3') using the Maxima Sybr Green qPCR MM Rox (Thermo Fisher Scientific, USA) on a LightCycler ${ }^{\mathbb{R}} 480$ System (Roche Life Science, USA). The final concentrations of each primer used were $50 \mathrm{nM}$. PCR cycling conditions used were as follows: initial $50^{\circ} \mathrm{C}$ for 2 min, then $95^{\circ} \mathrm{C}$ for $10 \mathrm{~min}$, followed by $95^{\circ} \mathrm{C}$ for $30 \mathrm{~s}, 60^{\circ} \mathrm{C}$ for $1 \mathrm{~min}$ and $72^{\circ} \mathrm{C}$ for $30 \mathrm{~s}$ with real-time data acquisition for 40 cycles. Results were expressed using the comparative cycle threshold $(\mathrm{Ct})$ method, where the $\Delta \mathrm{Ct}$ was calculated as $\mathrm{Ct}_{\text {(gene of interest) }}-\mathrm{Ct}_{(\text {actin) }}$. The relative changes in the expression level of one specific gene $(\Delta \Delta \mathrm{Ct})$ were performed by subtraction of the average $\Delta \mathrm{Ct}$ of each sample with the $\Delta \mathrm{Ct}$ of CTR and the fold change was determined as $2^{-\Delta \Delta C t}$. 


\section{Immunoblotting and Densitometric}

\section{Analysis}

Total cellular proteins were extracted by lysing the cells in icecold RIPA lysis buffer (Thermo Scientific, USA). Protein concentration was determined by the Bradford protein assay (Bio-Rad Laboratories, Inc., USA) using bovine serum albumin (BSA) (Sigma, USA) as the standard. Thirty $\mu \mathrm{g}$ of proteins per sample were subjected to sodium dodecyl sulfatepolyacrylamide gel electrophoresis (SDS-PAGE) and electrotransferred onto polyvinylidene fluoride (PVDF) membranes (Biorad, USA). Proteins of interest were detected by specific antibodies and visualized by Pierce ${ }^{\mathrm{TM}}$ ECL Western Blotting Substrate (Thermo Scientific, USA) using ChemiDoc ${ }^{\mathrm{TM}}$ MP Imaging System (Bio-Rad, USA) or autoradiography with Kodak films (USA).

Densitometric analysis was performed by quantifying the intensity of the bands using ImageJ (NIH, USA). $\beta$ actin was used as the loading control for normalizing the total amounts of proteins in the cell lysates.

\section{Antibodies and Chemicals}

The following primary antibodies were used for immunoblotting at the following concentrations: anti-actin $(1: 10,000)$ (Abcam, UK) and anti-Collagen 1 (1:1000, Thermo Fisher, USA). Secondary antibodies used for immunoblotting were goat anti-mouse and goat anti-rabbit horseradish peroxidaseconjugated IgG (1:10,000, Thermo Fisher, USA). Recombinant human TGF beta 1 (Abcam, USA) and lipofectamine 2000 Reagent (Thermo Fisher, USA) were used to treat cells and siRNA transfection, respectively.

\section{Dosimetry}

The In vitro Sedimentation, Diffusion and Dosimetry (ISDD) model was followed for performing particle dosimetry calculations. ${ }^{22}$ The effective density was derived using the volumetric centrifugation method described by DeLoid et al: $^{.23} 1 \mathrm{~mL}$ of $1 \mathrm{mg} / \mathrm{mL}$ suspension of HA particles in DMEM was kept in packed cell volume (PCV) tubes (Techno Plastic Products (TPP), Trasadingen, Switzerland) and centrifuged in bench-top swing-out rotor centrifuge at $2000 \mathrm{~g}$ for 1 hour. From the pellet obtained, the volume of the agglomerate pellet $\left(V_{\text {pellet }}\right)$ was measured with the help of a slide-rule-like easy measure device which was also provided by the PCV tube manufacturers. The $V_{\text {pellet }}$ value was used to determine the effective density $\left(\rho_{\mathrm{EV}}\right)$ using the following equation:

$$
\rho E V=\rho m e d i a+\left[\left(\frac{\text { Menm }}{V \text { pelletSF }}\right)\left(1-\left(\frac{\rho \text { media }}{\rho E N M}\right)\right]\right.
$$

where $\rho_{\text {media }}$ is the density of media, $M_{\mathrm{ENM}}$ is the mass of particles, $V_{\text {pellet }}$ is the volume of the pellet, $\mathrm{SF}$ is the stacking factor and $\rho_{\mathrm{ENM}}$ is the density of particles.

\section{Endotoxin Assay}

Three hundred $\mu \mathrm{g} / \mathrm{mL}$ HA particles were suspended in DMEM (with 10\% FBS and antibiotics) and incubated for 1, 3, 5, and 7 days. The supernatant was collected each day and subjected to Pierce ${ }^{\mathrm{TM}}$ LAL Chromogenic Endotoxin Quantitation Kit (Thermo Scientific; USA). The kit protocol was followed for the subsequent steps.

\section{Statistical Analysis}

All results are presented as mean \pm SEM and represent a minimum of three independent experiments of $n=3$, unless otherwise stated. Statistical significance of the difference between the two groups was determined by the two-tailed unpaired Student's $t$-test and considered significant if $p<0.05$.

\section{Results}

\section{Size and Charge Characterization of HA Particles}

The different factors that influence cellular uptake of particles are particle size, shape, and surface characteristics such as charge and hydrophobicity. ${ }^{20,24}$ The hydrodynamic size of the HA particles was determined using dynamic light scattering (DLS) and it was revealed that there were two different populations - the majority of the particles were $100-1000 \mathrm{~nm}$ and a smaller population was greater than $1000 \mathrm{~nm}$ in size (Supplementary Figure 1A). The polydispersity index (PDI) of the sample was 0.741 , indicating a very broad size distribution. However, hydrodynamic sizes account for particle agglomeration and the surrounding solvent-solute corona. Therefore, the pristine particle size was measured using transmission electron microscopy (Supplementary Figure 1B). Individual particle diameters were quantified, and it was observed that $8 \%$ of the particles were less than $100 \mathrm{~nm}, 15 \%$ were $100-150$ $\mathrm{nm}, 65 \%$ were $150-200 \mathrm{~nm}, 8 \%$ were $200-250 \mathrm{~nm}$ and the rest were greater than $250 \mathrm{~nm}$ in size (Supplementary Figure 1C). Henceforth, all subsequent studies were conducted with the aforementioned poly-dispersed suspension of HA particles. 


\section{Dosimetric Analysis of HA Particles}

HDFs were exposed to the particles at an administered dose of $300 \mu \mathrm{g} / \mathrm{mL}$ based on cell viability assays (data not shown). However, in the case of nano-sized particles, due to the various driving forces of diffusion (due to Brownian motion) and sedimentation (due to gravitational force), the effective dose exposed to the cells will vary over time, volume of media and surface area of the culture plate format compared to the administered dose. Hence, we used the ISDD model by Hinderliter et al to calculate the effective dose which is a fraction of the administered dose at a given point of time. The ISDD model is a computational model of dosimetry developed for nanoparticle and agglomerate kinetics in 2-dimensional cell culture systems. ${ }^{22}$ Herein, we used the ISDD model together with the volumetric centrifugation method to measure the effective density $\left(\rho_{\mathrm{EV}}\right),{ }^{23}$ so as to determine: 1$)$ the time-weighted exposure (TWE) level, which is based on the mass of particles per unit area of culture over the entire culture time period; 2) the time-weighted average (TWA) exposure levels, which is based on the mass of particles per unit area of culture per unit time. The effective density was calculated to be 1.411 $\mathrm{g} / \mathrm{cm}^{3}$ for HA particles in DMEM with $10 \%$ FBS. Using this effective density, the fraction of particles sedimented (fD) over different time points was calculated for different cell culture plate formats. Subsequently, fD was plotted against incubation time $(t)$ and the area under the curve (AUC) was measured, having the unit fraction.hr. Combining this AUC for each time point with the absolute administered dose (in $\mu \mathrm{g} / \mathrm{cm}^{2}$ ) of particles in a particular plate format, we got the TWE dose with the unit $\left(\mu \mathrm{g} / \mathrm{cm}^{2}\right) . h r$. To get the average dose at a time point, we divided the TWE with the number of hours to arrive at the TWA dose having the unit $\mu \mathrm{g} / \mathrm{cm}^{2}$. Such an approach allows accurate determination of the effective dose of particles that adherent cells at the bottom of culture vessels are actually exposed to. This is discussed in more detail in our earlier publication. ${ }^{25}$ Supplementary Table 1 lists the AUC, TWE, and TWA levels for different plate formats at various incubation time points.

\section{Internalization of HA Particles and Proliferation of Primary Human Dermal Fibroblasts}

The rate of proliferation of HDFs was studied at the administered dose of $300 \mu \mathrm{g} / \mathrm{mL}$ of HA particles. Untreated (CTR) and HA treated cells were subjected to a Real-time Cell Analyzer (RTCA) over a period of 168 hours (7 days).
Endotoxin levels in the working solutions were also measured to eliminate the possibility of bacterial endotoxins in HA particles confounding the results (Supplementary Figure 2A). There was no significant cell loss or change in the rate of proliferation upon treatment with HA particles at the given concentration, compared to CTR (Figure 1A). In order to rule out impedance caused by sedimentation of HA particles on the RTCA electrodes, additional wells with only HA particles suspended in DMEM were analyzed. It was noted that HA particles alone did not interfere with impedance measurement, with the values recorded being comparable to wells containing only DMEM. Subsequently, primary HDFs were exposed to the same administered dose of FITC-tagged HA particles to characterize their uptake by the cells. HDFs were untreated (CTR) or treated with FITC-tagged HA particles for $24\left(\mathrm{TWA}=43.4 \mu \mathrm{g} / \mathrm{cm}^{2}\right), 72$ $\left(\mathrm{TWA}=54.4 \mu \mathrm{g} / \mathrm{cm}^{2}\right), 120\left(\mathrm{TWA}=56.6 \mu \mathrm{g} / \mathrm{cm}^{2}\right)$ and 168 $\left(\mathrm{TWA}=57.5 \mu \mathrm{g} / \mathrm{cm}^{2}\right)$ hours $(1,3,5$ and 7 days, respectively). Confocal microscopy images revealed the presence of FITC-tagged HA particles inside the cells from day 1, which increased on day 3 and day 5, and subsequently declined by day 7 (Supplementary Figure 3A). A quantitative study of cellular uptake of the particles was done by flow cytometry. Our results indicated that the cells could uptake HA particles within 6 hours (TWE dosage $=$ $13.9 \mu \mathrm{g} / \mathrm{cm}^{2}$ ) of exposure; showing maximum uptake at 72 hours (TWA $=54.4 \mu \mathrm{g} / \mathrm{cm}^{2}$; day 3), following which there was a decline at 120 hours (TWA $=56.6 \mu \mathrm{g} / \mathrm{cm}^{2}$; day 5 ) and 168 hours $\left(\mathrm{TWA}=57.5 \mu \mathrm{g} / \mathrm{cm}^{2}\right.$; day 7) (Figure 1B). To study whether the internalized particles were cleared by the cells after day 3 or if the drop in FITC signal was due to quenching, TEM was performed. TEM micrographs showed endosomal uptake of the HA particles by HDFs at 72 hours (TWA $=54.4 \mu \mathrm{g} / \mathrm{cm}^{2}$; day 3 ) evident from particle localization in endosomes or vacuoles in the cytoplasm (Figure $1 \mathrm{C}$ top). At 168 hours (TWA $=57.5 \mu \mathrm{g} / \mathrm{cm}^{2}$; day 7) particles were either still localized in lysosomes and vacuoles or appeared to be eliminated by exocytosis, based on compartmentalization in secretory vesicles or exosome-like organelles (Figure 1C bottom). Various particles like gold, cerium dioxide, and titanium dioxide have been reported to be exocytosed by cells depending on their size, shape, and surface charge. ${ }^{26-28}$ It is possible that exocytosis of the particles occurred by day 7 , leading to the decline in the number of particles present in the cytosol, as observed from our flow cytometry results. 


\section{A}

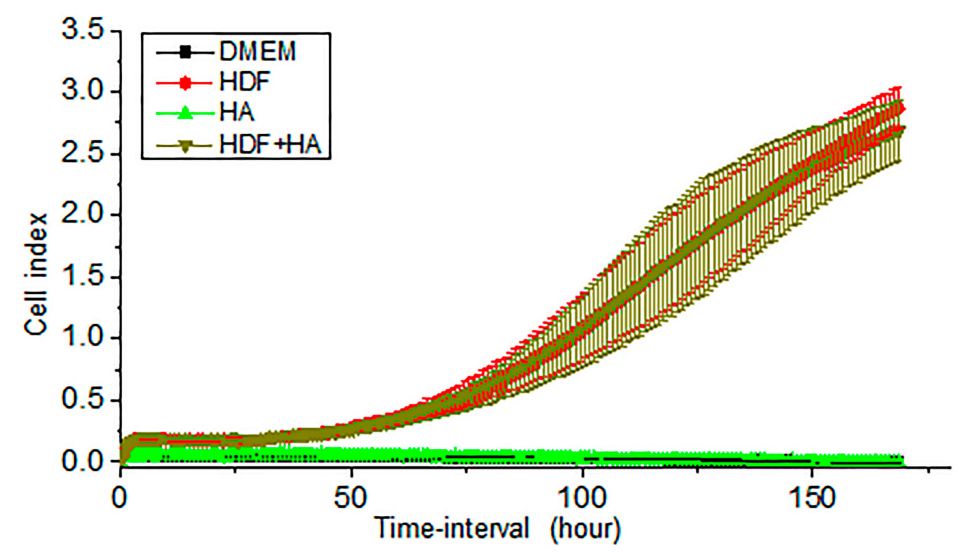

B
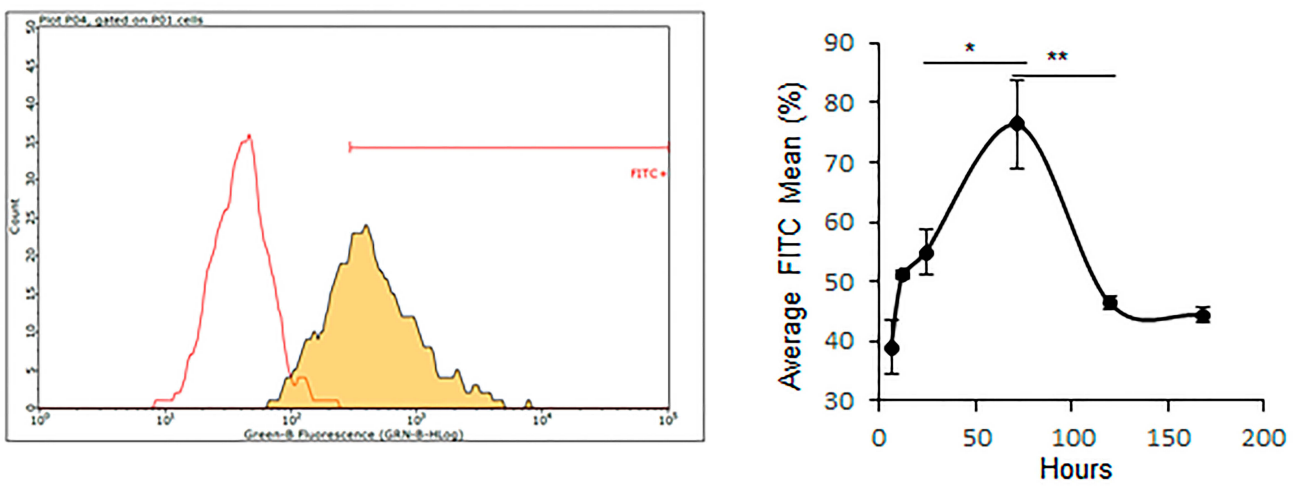

C

CTR

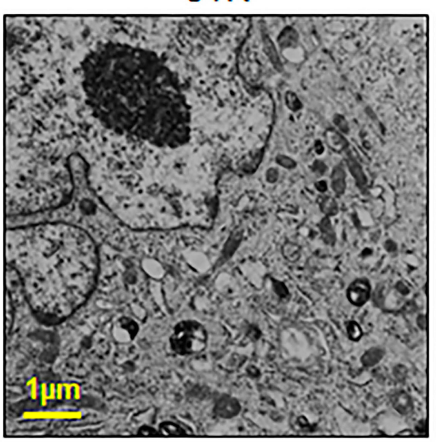

DAY $3 \mathrm{HA}$

CTR

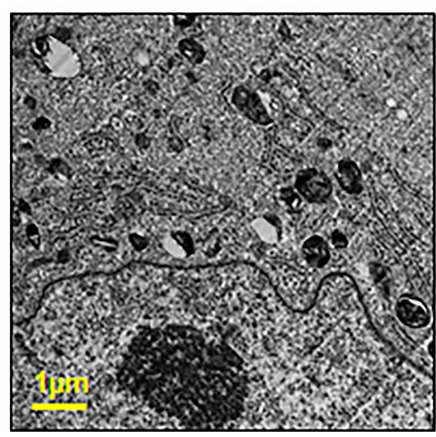

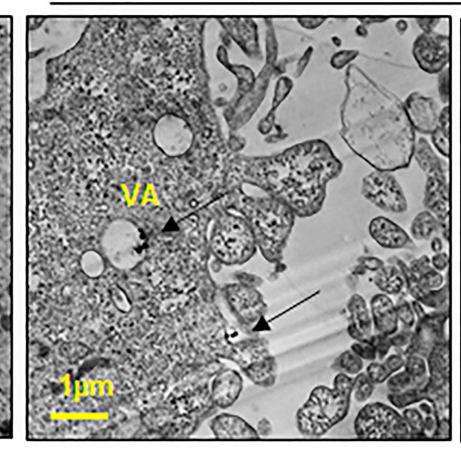

DAY 7 HA
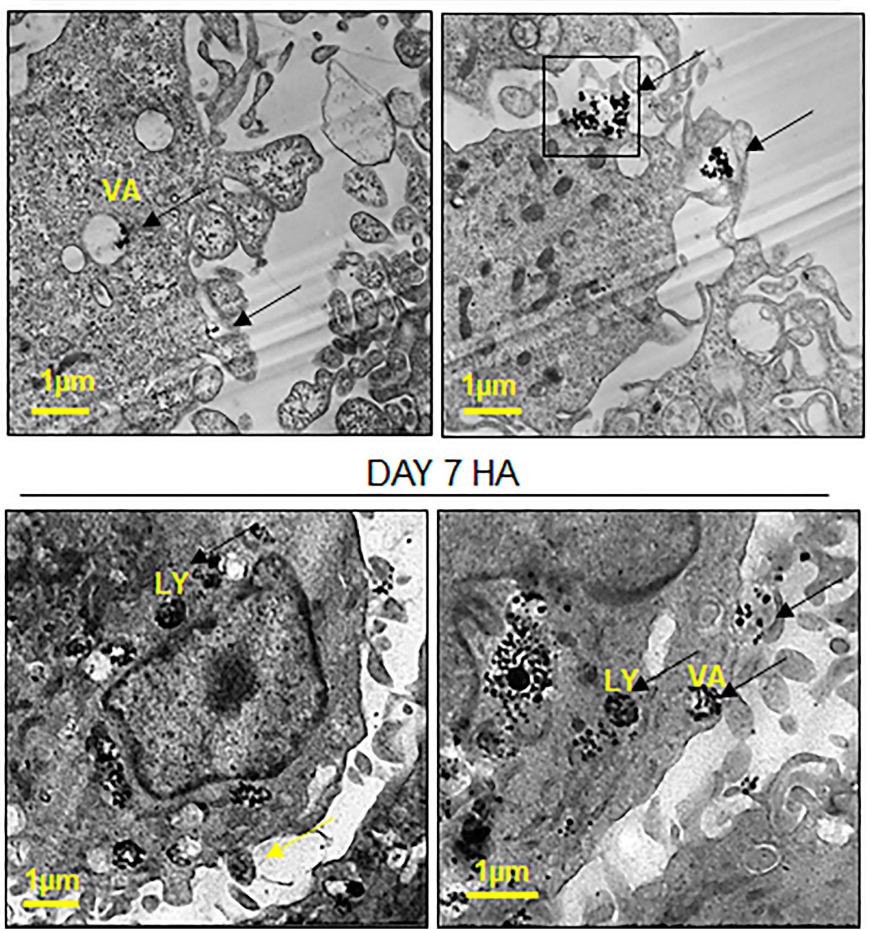

Figure I Uptake and viability of hydroxyapatite particles by HDFs. Primary HDFs were exposed to HA particles at the administered dose of $300 \mu g / m L$ to evaluate cell viability and proliferation. (A) Results of Real-time Cell Analyzer (RTCA) experiments over 7 days show that there was no significant difference in cell index in HDFs with or without exposure to HA particles. DMEM alone and HA particles in DMEM (HA) were used as negative controls. (B) Flow cytometry analysis of untreated control (CTR) and FITC-HA treated cells to quantify the percentage of cells that have internalized HA particles over $6\left(\right.$ TWA $\left.=13.9 \mu \mathrm{g} / \mathrm{cm}^{2}\right), 12\left(\right.$ TWA $\left.=27.4 \mu \mathrm{g} / \mathrm{cm}^{2}\right), 24\left(\right.$ TWA $\left.=43.4 \mu \mathrm{g} / \mathrm{cm}^{2}\right), 72\left(\right.$ TWA $\left.=54.4 \mu \mathrm{g} / \mathrm{cm}^{2}\right), 120($ TWA $=56.6$ $\mu \mathrm{g} / \mathrm{cm}^{2}$ ), and 168 (TWA $=57.5 \mu \mathrm{g} / \mathrm{cm}^{2}$ ) hours, respectively. (C) Transmission electron micrographs of CTR (left) and HA treated cells (middle and right), after 3 days (top) and 7 days (bottom) of treatment. LY, lysosomes; VA, vacuoles; arrows, HA particles. Quantitative values are expressed as means $\pm \mathrm{SEM}, \mathrm{n}=3$. $* p<0.05$ and $* * p<0.005$, compared to CTR. 


\section{Suppression of Pro-Inflammatory and} Pro-Collagenic Cytokines by HA Particles

To investigate pro-inflammatory responses, primary HDFs were exposed to HA particles for 72 hours (TWA $=54.4$ $\mu \mathrm{g} / \mathrm{cm}^{2}$; day 3) and the supernatants were collected to assay the amount of pro-inflammatory cytokines released. Surprisingly, it was noted that there was reduced secretion of different pro-inflammatory cytokines (Figure 2A-C). Interestingly, it was observed that the levels of various secreted pro-collagenic cytokines declined (Figure 2A and C). Specifically, certain cytokines like monocyte chemoattractant protein-1 (MCP-1), Rantes, and Eotaxin-1, all of which regulate transforming growth factor beta (TGF-
B1) levels, decreased by $25 \%, 30 \%$, and $25 \%$, respectively. As a result, there was a $25 \%$ reduction in TGF- $\beta$ levels as well. Apart from these, there was a decline in the secretion of Interleukin-6 (IL-6), Eotaxin-2, Interferon gammainduced Protein-10 (IP-10) and Interleukin-8 (IL-8), all of which have been reported to regulate cellular production of collagen. The most commonly known inducer of Collagen 1 is TGF- $\beta$, which is multifunctional and plays a central role in tissue fibrosis by increasing the synthesis of collagen or fibronectin. ${ }^{17,29,30}$ Reduction in the levels of TGF- $\beta$ could be an indicator of lower Collagen 1 synthesis by the HDFs. Although our results showed high reproducibility and low standard errors in the majority of the
A

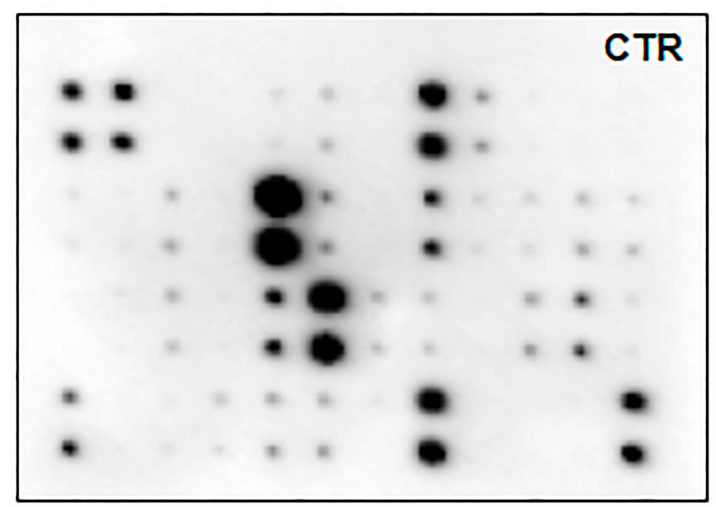

B

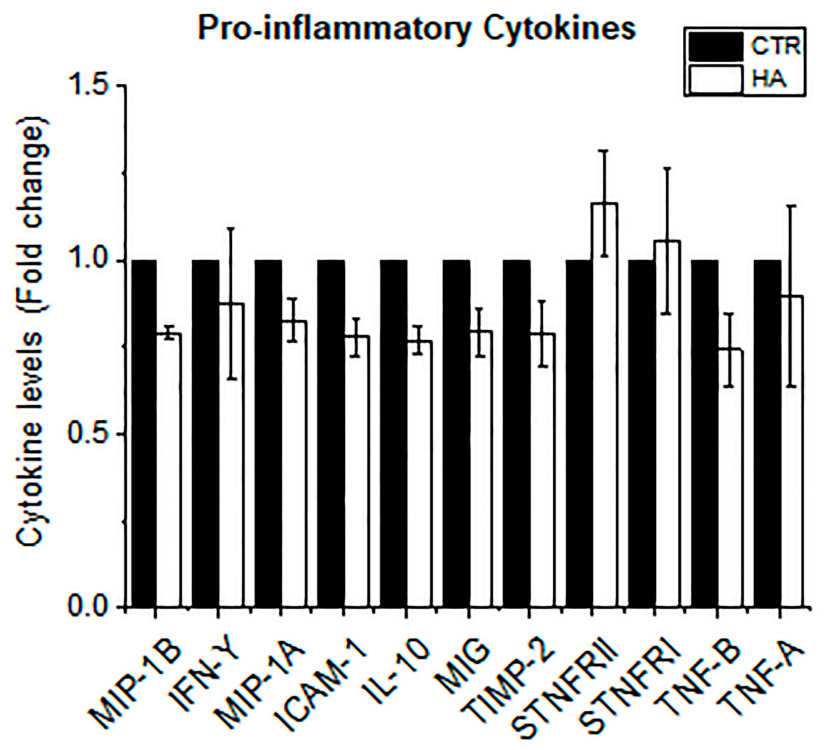

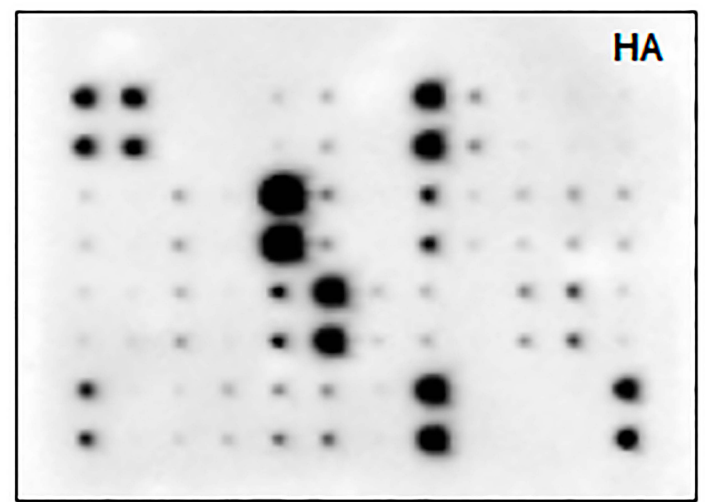

C

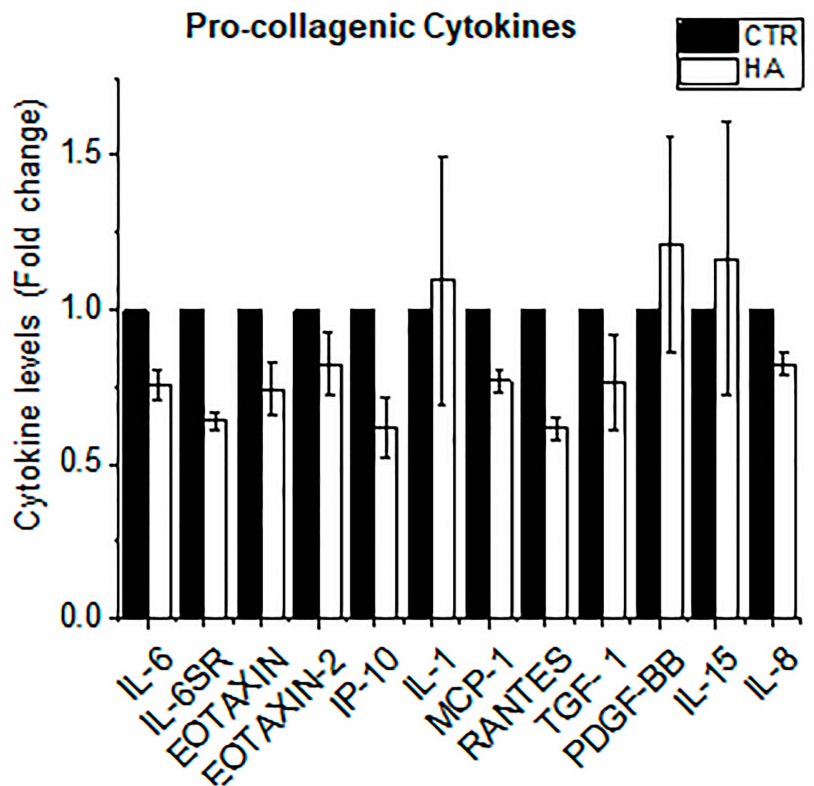

Figure 2 Reduced secretion of pro-inflammatory cytokines upon exposure to HA particles. Primary HDFs were exposed to HA particles at the administered dose of 300 $\mu \mathrm{g} / \mathrm{mL}$ to study the release of pro-inflammatory cytokines. (A) Representative cytokine array blots showing the levels of various pro-inflammatory cytokines secreted by untreated HDFs (CTR) or HDFs exposed to HA particles for 3 days. (B) Graph shows the levels of different pro-inflammatory and (C) pro-collagenic cytokines secreted by CTR or HA exposed cells for 3 Days. Quantitative values are expressed as means \pm SEM, $n=2$. 
cytokines, we could only produce two biological replicates. Hence, to further validate the results, we performed various quantitative analyses of cellular collagen secretion, expression, and translation, which are discussed in the next section.

\section{Reduced Collagen Expression and Secretion Upon Exposure to HA Particles}

In response to the reduced secretion of TGF- $\beta$ and other pro-collagenic cytokines, the secretion profile of Collagen 1 was examined. Primary HDFs were exposed to $300 \mu \mathrm{g} /$ $\mathrm{mL}$ administered dose of HA particles and the amount of secreted Collagen 1 in the cell culture supernatant was assessed by ELISA after $24\left(\right.$ TWA $\left.=43.4 \mu \mathrm{g} / \mathrm{cm}^{2}\right), 72$ $\left(\right.$ TWA $\left.=54.4 \mu \mathrm{g} / \mathrm{cm}^{2}\right), 120\left(\right.$ TWA $\left.=56.6 \mu \mathrm{g} / \mathrm{cm}^{2}\right)$ and 168 $\left(\mathrm{TWA}=57.5 \mu \mathrm{g} / \mathrm{cm}^{2}\right)$ hours $(1,3,5$ and 7 days, respectively) of treatment. Exposure to HA particles resulted in a significant reduction of secreted Collagen 1 at all the time points (Figure 3A). This decrease in Collagen 1 secretion could be due to a reduction of transcriptional Collagen 1 expression or a reduction of translation by HDFs upon HA exposure. Hence, the transcriptional expression of Collagen 1 was further studied by real-time quantitative PCR (RT-qPCR). Cells were treated similarly, and it was observed that there was $45 \%, 70 \%$, and $60 \%$ reduction in expression of coll $\alpha 1$ gene on 24,72 and 168 hours (days 1, 3, and 7) post-treatment, respectively (Figure 3B). Furthermore, these results were corroborated by Western blot analysis of Collagen 1 protein levels at the various time points. Densitometry analysis of the immunoblots revealed $25 \%, 60 \%, 30 \%$, and $40 \%$ reduction in Collagen 1 levels in the HA particles treated cells at 24 $\left(\right.$ TWA $\left.=41.8 \mu \mathrm{g} / \mathrm{cm}^{2}\right), 72\left(\right.$ TWA $\left.=47.2 \mu \mathrm{g} / \mathrm{cm}^{2}\right), 120$ $\left(\mathrm{TWA}=48.2 \mu \mathrm{g} / \mathrm{cm}^{2}\right)$, and $168\left(\mathrm{TWA}=48.7 \mu \mathrm{g} / \mathrm{cm}^{2}\right)$ hours (1, 3, 5 and 7 days), respectively (Figure $3 \mathrm{C}$ and D). Interestingly, upon normalizing the levels of Collagen 1 expression on day 5 to day 3 , it was revealed that there was a significant recovery of cellular Collagen 1 levels by day 5 (Figure 3D). Since this recovery of Collagen 1 expression at day 5 corresponded to a significant reduction in the uptake of HA particles at the same time (Figure 1B), cellular uptake of HA appeared to correlate inversely to Collagen 1 expression. Upholding the reduction in levels of pro-collagenic cytokines, our studies have thus confirmed that there was a reduction in mRNA expression, cellular collagen protein levels and secretion of Collagen 1 protein in HDFs upon exposure to HA particles over a period of 1 to 7 days.

\section{Loss of Collagen Expression is a HA Particle Specific Phenomenon}

Further studies were conducted to verify whether the effects on cellular collagen levels were HA particle specific. Primary HDFs were exposed to the same administered dose of $300 \mu \mathrm{g} / \mathrm{mL}$ of various particles, namely, HA (polydispersed fraction), silicon dioxide $\left(\mathrm{SiO}_{2}\right.$; mean size $=$ 20-50 nm), titanium dioxide $\left(\mathrm{TiO}_{2} ;\right.$ mean size $\left.=20 \mathrm{~nm}\right)$ and silver $(\mathrm{Ag}$; mean size $=24 \mathrm{~nm})$ for 24,72 , and 168 hours $(1,3$, and 7 days, respectively). It was noted that while there was a significant reduction of collal gene expression upon exposure to HA particles, there was no change in collal gene expression in cells exposed to $\mathrm{SiO}_{2}, \mathrm{TiO}_{2}$, or Ag particles (Figure 4A). Apart from particle-specific effects, the species- and tissue-specificity of the anti-collagenic properties of HA particles was also investigated. Three hundred $\mu \mathrm{g} / \mathrm{mL}$ of HA particles were administered to primary HDFs, primary human conjunctival fibroblasts (HCFs), and primary mouse conjunctival fibroblasts $(\mathrm{MCFs})$ for 24 (TWA $\left.=43.4 \mu \mathrm{g} / \mathrm{cm}^{2}\right), 72$ $\left(\mathrm{TWA}=54.4 \mu \mathrm{g} / \mathrm{cm}^{2}\right)$, and $168\left(\mathrm{TWA}=57.5 \mu \mathrm{g} / \mathrm{cm}^{2}\right)$ hours $(1,3$, and 7 days, respectively). On day 1 , there was a significant reduction of collal expression in HDFs and MCFs but no change in HCFs (Figure 4B). On day 3, there was a significant reduction in coll $\alpha 1$ expression in HCFs and a recovery of collal levels in MCFs (Figure 4C). On day 7, both HDFs and HCFs showed reduced coll $\alpha 1$ expression, but there was no change in MCFs (Figure 4D). This provides insights into the fact that HA particles have anti-collagenic effects on various cells, although the rate of onset and duration of the effects may vary depending on tissue type or species. In addition to coll $\alpha 1$, the effects of col3 and col5 expression were also studied. While there was an increased transcriptional expression of col3 (Figure 4E) on day 1 and day 3, col5 expression increased on day 3 and day 5 instead (Figure 4F).

The effects of the HA particles on Collagen 1 levels were independent of particle size distribution; both mono-dispersed and poly-dispersed particle fractions elicited similar levels of Collagen 1 reduction (Figure 3B and Supplementary Figure 2D). Centrifugal field flow fractionation (CFFF) was used to broadly fractionate the polydispersed HA particles based on their sizes, and the dominant, smaller sized population was eluted. It was found that the majority of the particles 
A
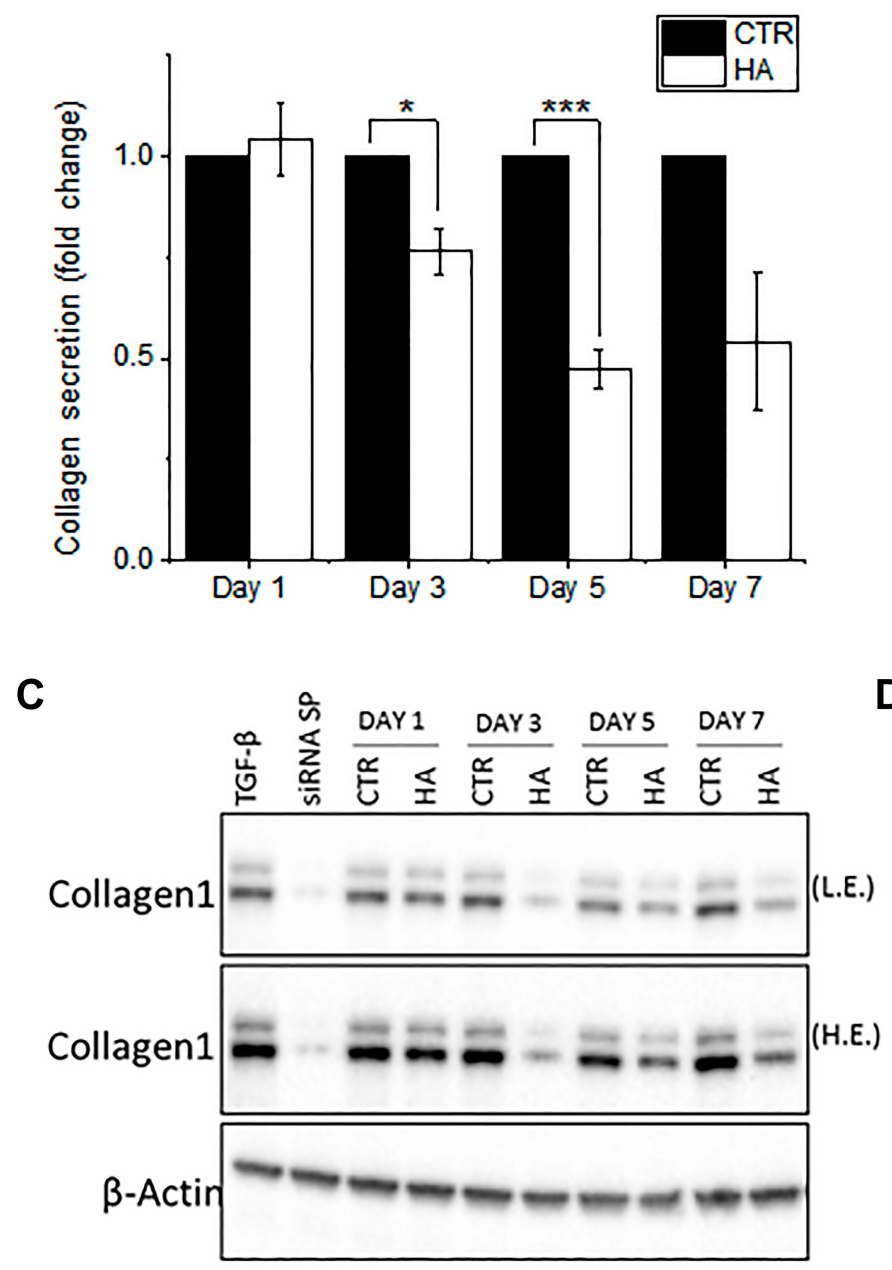

B
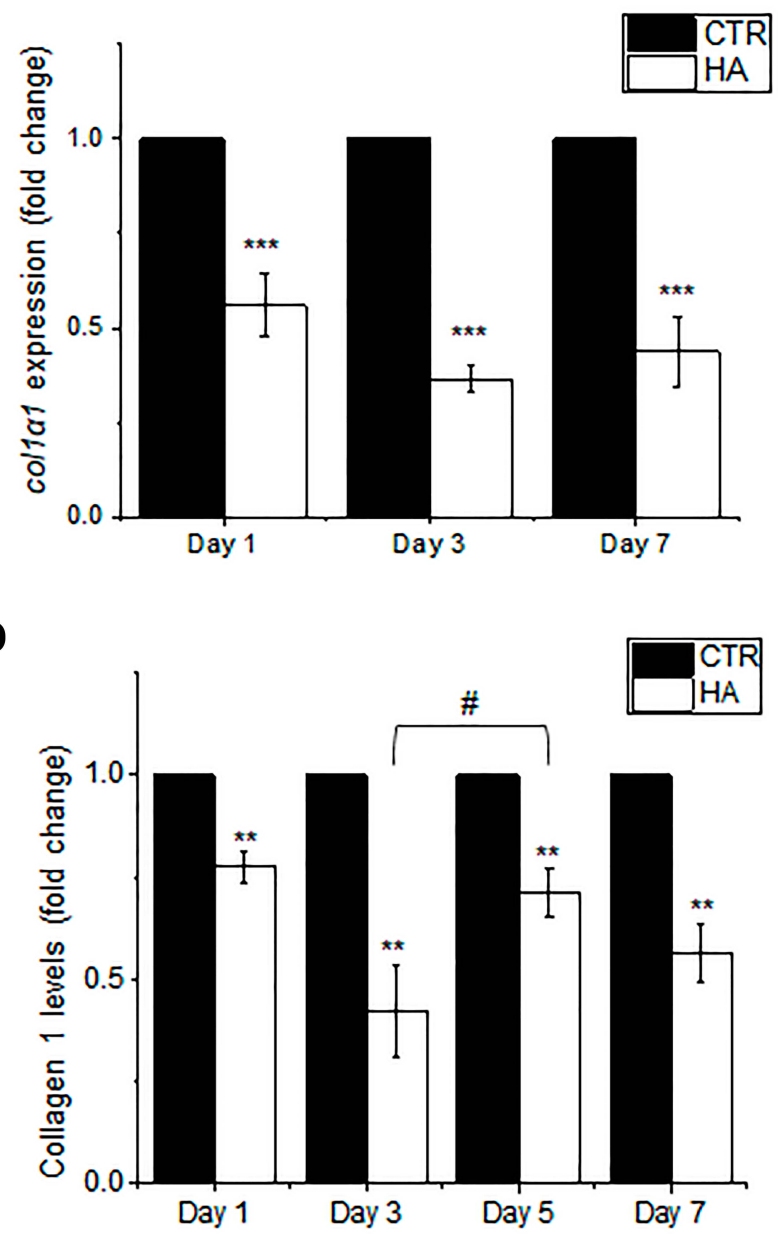

Figure 3 Reduced collagen production and secretion upon exposure to HA particles. Primary HDFs were exposed to HA particles at the administered dose of $300 \mu \mathrm{g} / \mathrm{mL}$ to study the effects on Collagen I levels. (A) Graph shows the levels of Collagen I secreted by untreated HDFs (CTR) or HDFs exposed to HA particles for I, 3, 5 and 7 days. (B) Graph shows the levels of expression of collal gene in untreated HDFs (CTR) or HDFs exposed to HA particles for I, 3 and 7 days. (C) Representative immunoblots showing the levels of Collagen I in CTR and HA treated cells for I, 3, 5 and 7 days, normalized against $\beta$-Actin. Cells were treated with TGF- $\beta$ as positive control and transfected with siRNA sparc (siRNASP) as negative control. (D) Graph shows densitometry analysis of Collagen I protein levels in CTR or HA treated cells for I, 3, 5 and 7 days. Quantitative values are expressed as means \pm S.E.M, $n=3$. Differences are significant for $* p<0.05$, $* * p<0.005$ and $* * * p<0.0005$, compared to CTR and $\# p<0.05$ compared to day 3 .

Abbreviations: LE, low exposure; HE, high exposure.

were eluted at size $\leq 100 \mathrm{~nm}$ (Supplementary Figure 2B) The sizes were validated by DLS size measurement (Supplementary Figure 2B) and TEM (Supplementary Figure 2C). Additionally, the eluted fraction was administered to HDFs for 3 days to study coll $\alpha 1$ expression. The results were in agreement with that obtained when we exposed HDFs to polydispersed HA particles before fractionation (Supplementary Figure 2D). This reduction of Collagen 1 was an effect limited only to HA particles, as shown by the comparison with other particles (Figure 4A). Upon assessment with different cell types, it was further revealed that the effect was also cell-specific (Figure 4B-D).

\section{Discussion}

In this study, we have demonstrated the specific outcomes of HA particle interaction with primary HDFs, as a model for understanding the potential physiological effects of cell-particle interactions beyond cytotoxicity. Polydispersed hydroxyapatite particles were used as a model and were exposed to primary HDFs. Owing to the small size $(\sim 100-1000 \mathrm{~nm})$ and slight negative charge $(\sim-13 \mathrm{mV}$ zeta potential) of the particles, they are readily internalized by HDFs. Although the cell membrane is negatively charged, previous studies have shown that various negatively charged particles are readily endocytosed with the help of local positively charged 
A

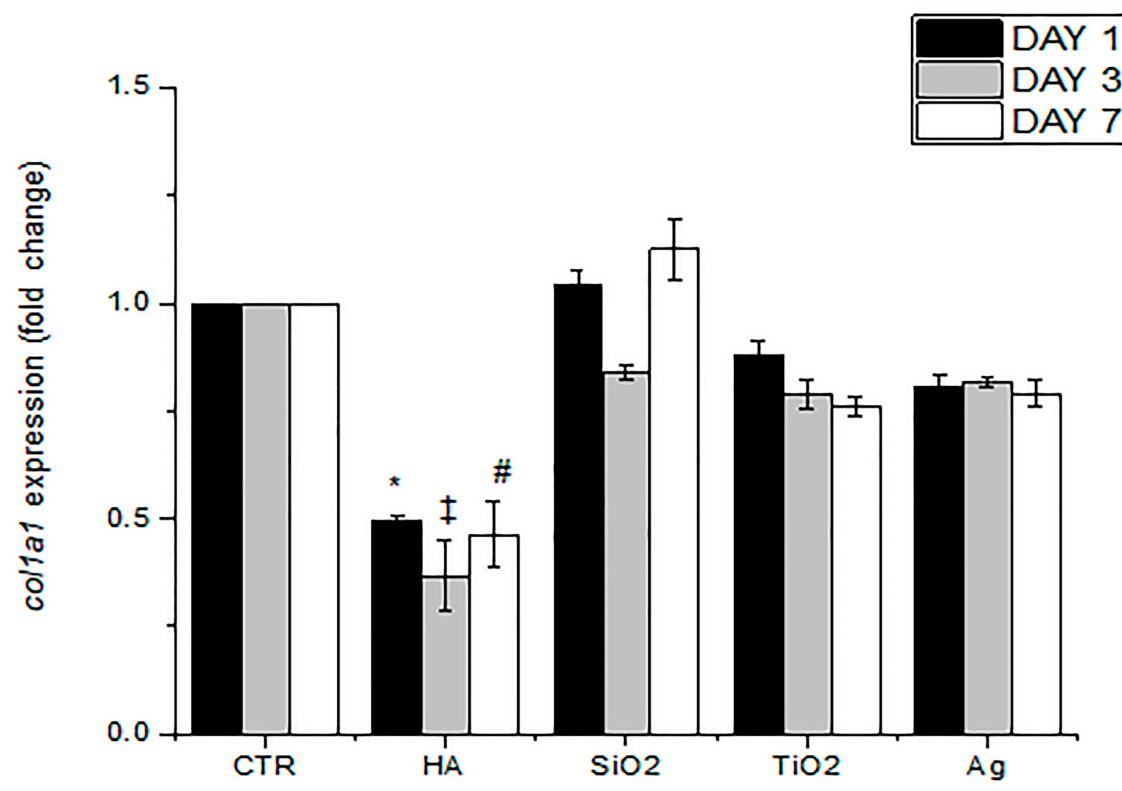

B

DAY 1

C

$\underline{D A Y} 3$

D

DAY 7
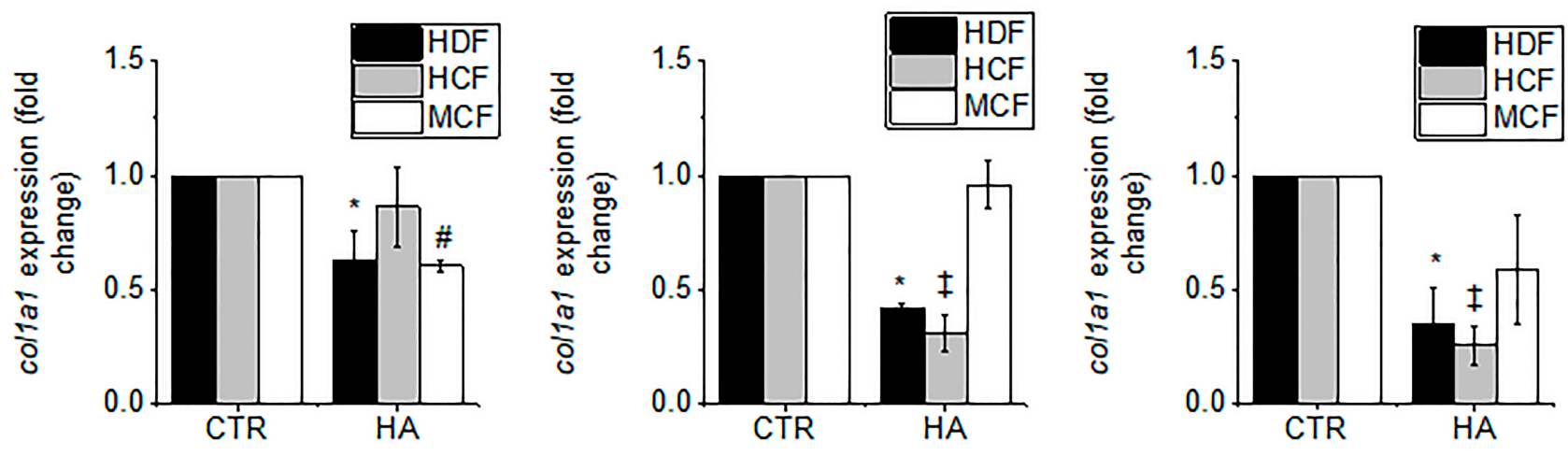

E

F
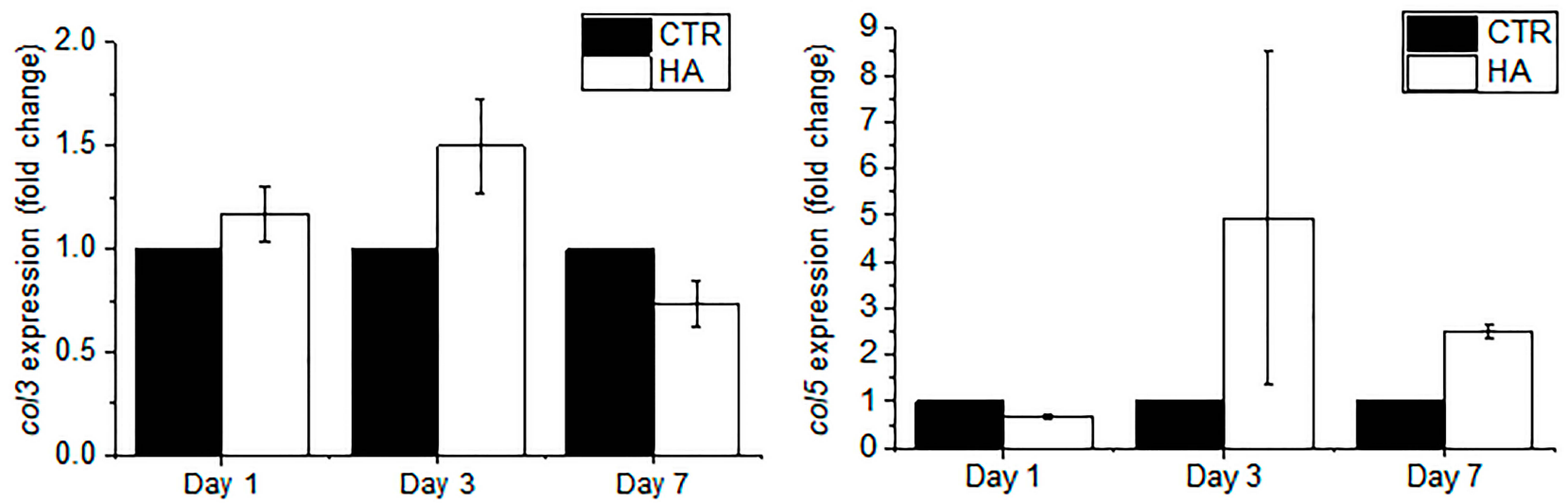

Figure 4 HA particles reduce coll $\alpha$ I gene expression in primary HDFs, HCFs and MCFs. (A) Graph shows the levels of coll $\alpha /$ gene expression at days I, 3 and 7 in untreated controls (CTR) and $\mathrm{HA}, \mathrm{SiO}_{2}, \mathrm{TiO}_{2}$ and $\mathrm{Ag}$ particle treated cells. Graphs show the levels of coll $\alpha /$ gene expression at (B) day I, (C) day 3 and (D) day 7 in untreated (CTR) and HA treated HDFs, HCFs and MCFs. (E) Levels of col3 and (F) col5 gene expression at day I, day 3 and day 7 in untreated (CTR) and HA treated HDFs. Quantitative values are expressed as means \pm S.E.M, $\mathrm{n}=3 .{ }^{*},{ }^{\ddagger}$, ${ }^{\#}$ Stand for $p<0.05$ compared to CTR in HDFs, HCFs and MCFs, respectively. 


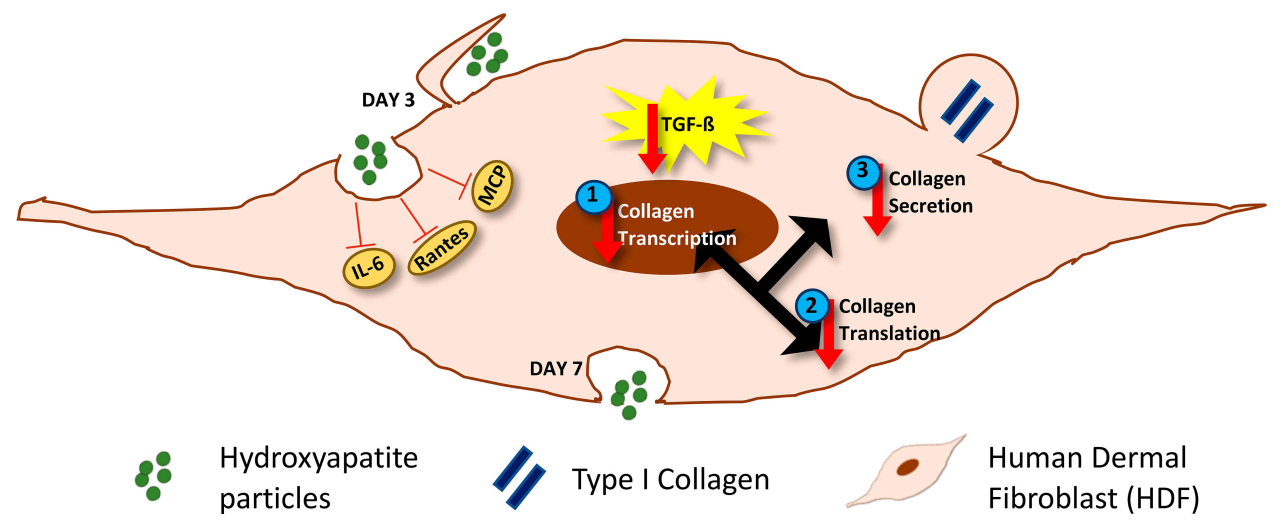

Figure 5 Schematic representation of the effects of HA particles on HDFs. HA particles are readily internalized by primary HDFs by endocytosis. Maximum internalization occurs by day 3 post-exposure, by macropinocytosis. Exposure to HA particles ensures reduced levels of various pro-inflammatory and pro-collagenic cytokines like IL-6, MCP and Rantes. It also caused a decrease in TGF- $\beta$ levels. Furthermore, there was a decrease in (I) transcriptional expression, (2) translation and (3) secretion of Collagen I in HDFs. The particles are exocytosed by 7 days post-exposure.

regions of the cell membrane. ${ }^{2}$ Various cells may employ various endocytic pathways to internalize the same or different particles. Fibroblasts most commonly employ caveolaedependent endocytosis for internalization, ${ }^{31,32}$ as evidenced by the presence of the caveolin-1 protein in these cells. ${ }^{32}$ It is commonly noted that particles that are internalized by the caveolae-mediated pathway may bypass the lysosomes and are deposited in the endoplasmic reticulum or Golgi apparatus. ${ }^{33-35}$ Another major pathway for particle internalization by fibroblasts is macropinocytosis, where uptake of surrounding fluids takes place by large vacuoles. The vacuoles ultimately fuse with other organelles like lysosomes or travel back to the cellular surface. They are then released into the extracellular matrix by fusing with the cell membrane, although the fate of macropinocytosed particles remains unclear. $^{36-38}$ In addition, there are other less common endocytic pathways employed by dermal fibroblasts like clathrin-mediated endocytosis and clathrincaveolae-independent endocytosis. ${ }^{39}$ The exact uptake pathway can be identified by treatment with specific inhibitors like amiloride- $\mathrm{HCl}$, amantadine- $\mathrm{HCl}$, or genistein. ${ }^{40-42}$ Amiloride- $\mathrm{HCl}$ can inhibit the internalization of particles via macropinocytosis; ${ }^{40}$ amantadine- $\mathrm{HCl}$ prevents budding of clathrin-coated pits inhibiting clathrin-mediated endocytosis; ${ }^{41}$ and genistein impairs caveolae-mediated uptake by blocking tyrosine kinases of the Src-family. ${ }^{42}$ In this study, we performed TEM to get an overall idea about the cellular localization, uptake, and release of the HA particles. TEM images of HDFs exposed to HA particles for 3 days suggest macropinocytosis as the mode of internalization owing to the localization of the particles in vacuoles and macropinosome-like structures at the cellular surfaces.
Furthermore, the TEM images of cells after 7 days of HA exposure suggest lysosomal and vacuolar localization as well as exocytosis of the HA particles. Cell morphology, membrane integrity, and ultrastructures remained preserved throughout the 7 days of exposure. A similar study using variously sized silica particles exposed to dermal fibroblasts corroborates our results, suggesting that a macropinocytic process was occurring. ${ }^{43}$ In addition to cellular uptake, the persistence of the particles inside the cells governs the therapeutic efficacy of a carrier. The aim of various carriers is to deliver the cargo in a controlled and sustained manner, and hence the particles, may be desired to persist in the cellular environment over long periods of time. Hence, our study was conducted over a period of 7 days.

When particles come into contact with biofluids, various macromolecules bind to, or get adsorbed onto, the surface, forming a "corona." 44 The cells "see" the particles as corona coated entities, and based on the composition of the corona, the cell decides how to react with the specific particles. ${ }^{45}$ There are three major factors that define the biological identity of a particle in the cellular environment: 1) physicochemical properties of the particle itself like size, shape, charge, dispersity, surface chemistry, and hydrophobicity/hydrophilicity; 2) biological factors like composition of the corona, cell type, and cellular environment; and 3) external factors like temperature, osmolarity, etc. ${ }^{38}$ Furthermore, it is also noted that cells may evoke pro-inflammatory reactions in response to foreign bodies such as the particles. Although HA is a biomaterial found in human tissues, it is ectopic to dermal fibroblasts as they are not exposed to these particles in physiological conditions. Consequently, exposure to HA particles for 3 days caused reduced secretion of various pro- 
inflammatory and pro-collagenic cytokines. Our studies indicate reduced secretion of numerous pro-inflammatory cytokines, which are reported to reduce Collagen 1 synthesis, like IL-6sR, IL-6, ${ }^{46} \mathrm{MCP}-1,{ }^{47}$ and Rantes. Levels of cytokine IL10 were also reduced, which should positively regulate MCP-1 and TGF- $\beta$ and induce an upregulation of Collagen 1 , according to studies in primary dermal fibroblasts. ${ }^{48}$ However, our studies suggest that in spite of a decrease in IL-10 levels, there was a reduction in the secretion of both MCP-1 and TGF- $\beta$, demonstrating that HA particles may independently reduce the levels of the said cytokines.

In this study, we explored the pro-inflammatory effects of commercially available poly-dispersed and spherical HA particles. While there remains scope for more in-depth analysis of the pathways involved, our study conclusively shows that HA particles impair the expression and synthesis of Collagen I in HDFs. This demonstration emphasizes the importance of testing various carrier particles in specific tissue environments, before application. However, it remains uncertain how the HA particles may reduce the secretion of various cytokines, and whether it is a result of certain microenvironments created inside the cells due to the formation of a corona or a direct effect of the HA particles. Additionally, the signaling pathways involved in causing the reduction of collagen levels remain unclear and deserve future exploration. For instance, pro-inflammatory cytokines like TGF- $\beta$, IL-4, and IL-13 may bind to receptors on fibroblast cell membranes and mediate pro-fibrogenic effects by regulating extracellular signal-regulated kinases (ERK) which may, in turn, regulate Collagen 1 synthesis. ${ }^{49}$ In a separate study, ICR mice were repeatedly administered silica nanoparticles intravenously, which resulted in pulmonary fibrosis. There was over-activation of JAK2/STAT3 and TGF- $\beta 1 / \mathrm{Smad} 3$ signaling pathways, leading to increased secretion of proinflammatory cytokines including TNF- $\alpha$, IL-1 $\beta$, and IL-6, resulting in increased collagen accumulation. ${ }^{50}$ Hence, it is possible that similar to silica nanoparticles, HA particles also modulate the JAK2/STAT3 and TGF- $\beta 1 / \mathrm{Smad} 3$ signaling pathways. The current study places more emphasis on the study of coll $\alpha 1$, col3, and col5 gene expressions. However, there is evidence that the cytokines TNF- $\alpha$ and TGF- $\beta$ can regulate the transcription of the coll $\alpha 2$ gene as well. ${ }^{51,52}$ While TGF- $\beta$ stimulates, nuclear factor kappa-light-chainenhancer of activated B cells (NF-kB) and TNF- $\alpha$ inhibit the transcription of coll $\alpha 2$ in a coordinated fashion in dermal fibroblasts. ${ }^{53}$ Thus, further studies on coll $\alpha 2$ expression may lead to important outcomes. This particular work will also benefit from further studies in vivo, that will account for endocrine signaling and macrophage mobilization which play a major role in eliciting a pro-inflammatory response. A technical limitation of this study is the challenge of obtaining particles of different chemical compositions with the same physicochemical properties, for a fair comparison. Regardless, our comparison of HA with other commonly explored particle types including $\mathrm{SiO}_{2}, \mathrm{TiO}_{2}$, and $\mathrm{Ag}$ nanoparticles provides an insight into the specific differential effects of HA on HDFs.

\section{Conclusion}

We demonstrated that HA particles do not affect HDF proliferation up to the administered dose of $300 \mu \mathrm{g} / \mathrm{mL}$ (maximum delivered dose of $94.2 \mu \mathrm{g} / \mathrm{cm}^{2}$ ). Further analysis pointed to the fact that prolonged exposure to HA particles can reduce the transcriptional expression, translation, and secretion of Collagen 1, which could compromise the integrity of the extracellular matrix. Figure 5 demonstrates the effects of HA particles on HDFs schematically. This study not only demonstrates the potential deleterious effects of exposure of fibroblasts to HA particles that go beyond basic cytotoxicity, but also highlights the need to contemplate different factors associated with specific particulate (nano)-carriers in the targeted cell or tissue environment where the intended function is to be realized.

\section{Funding}

Funding support: SingHealth-NTU-Research Collaborative Grant awarded to T.T.W. and K.W.N. (SHS-NTU/028/2016).

\section{Disclosure}

The authors declare no financial, commercial, or nonfinancial conflicts of interest in this work.

\section{References}

1. Salata OV. Applications of nanoparticles in biology and medicine. J Nanobiotechnology. 2004;2(1):3. doi:10.1186/1477-3155-2-3

2. Wu H, Li Z, Tang J, et al. The in vitro and in vivo anti-melanoma effects of hydroxyapatite nanoparticles: influences of material factors. Int J Nanomedicine. 2019;14:1177-1191. doi:10.2147/IJN.S184792

3. Jia J, Zhang S, Wen K, Li Q. Nano-scaled zeolitic imidazole framework-8 as an efficient carrier for the intracellular delivery of RNase A in cancer treatment. Int $J$ Nanomedicine. 2019;14:9971-9981. doi:10.2147/IJN. S210107

4. Albanese A, Tang PS, Chan WCW. The effect of nanoparticle size, shape, and surface chemistry on biological systems. Annu Rev Biomed Eng. 2012;14(1):1-16. doi:10.1146/annurev-bioeng-071811-150124

5. Tan YF, Mundargi RC, Chen MHA, et al. Layer-by-layer nanoparticles as an efficient siRNA delivery vehicle for SPARC silencing. Small. 2014;10(9):1790-1798. doi:10.1002/smll.201303201 
6. Mondal S, Dorozhkin SV, Pal U. Recent progress on fabrication and drug delivery applications of nanostructured hydroxyapatite. Wiley Interdiscip Rev Nanomed Nanobiotechnol. 2018;10(4):e1504. doi:10.1002/wnan.1504

7. Christoffersen J, Christoffersen MR. Kinetics of dissolution of calcium hydroxyapatite: V. The acidity constant for the hydrogen phosphate surface complex. J Cryst Growth. 1982;57(1):21-26. doi:10.1016/0022-0248(82)90244-5

8. Xu Q, Czernuszka JT. Controlled release of amoxicillin from hydroxyapatite-coated poly(lactic-co-glycolic acid) microspheres. J Control Release. 2008;127(2):146-153. doi:10.1016/j.jconrel.2008. 01.017

9. Rogers-Foy JM, Powers DL, Brosnan DA, Barefoot SF, Friedman RJ, LaBerge M. Hydroxyapatite composites designed for antibiotic drug delivery and bone reconstruction: a caprine model. J Investig Surg. 1999;12(5):263-275. doi:10.1080/089419399272386

10. Palazzo B, Iafisco M, Laforgia M, et al. Biomimetic hydroxyapatitedrug nanocrystals as potential bone substitutes with antitumor drug delivery properties. Adv Funct Mater. 2007;17(13):2180-2188. doi:10.1002/adfm.200600361

11. Rohanizadeh R, Chung K. Hydroxyapatite as a carrier for bone morphogenetic protein. J Oral Implantol. 2010;37(6):659-672. doi:10.1563/AAID-JOI-D-10-00005

12. Mulay SR, Anders H-J, Longo DL. Crystallopathies. $N$ Engl J Med. 2016;374(25):2465-2476. doi:10.1056/NEJMra1601611

13. McCarthy GM, Cheung HS. Point: hydroxyapatite crystal deposition is intimately involved in the pathogenesis and progression of human osteoarthritis. Curr Rheumatol Rep. 2009;11(2):141-147. doi:10.10 07/s11926-009-0020-6

14. Nakayama M. Macrophage recognition of crystals and nanoparticles. Front Immunol. 2018;9:103. doi:10.3389/fimmu.2018.00103

15. Laquerriere $P$, Grandjean-Laquerriere A, Jallot E, Balossier G, Frayssinet P, Guenounou M. Importance of hydroxyapatite particles characteristics on cytokines production by human monocytes in vitro. Biomaterials. 2003;24(16):2739-2747. doi:10.1016/S0142-9612(03) 00089-9

16. Jin C, Frayssinet P, Pelker R, et al. NLRP3 inflammasome plays a critical role in the pathogenesis of hydroxyapatite-associated arthropathy. Proc Natl Acad Sci U S A. 2011;108(36):14867-14872. doi:10.1073/pnas.1111101108

17. Sun JS, Tsuang YH, Chang WH, Li J, Liu HC, Lin FH. Effect of hydroxyapatite particle size on myoblasts and fibroblasts. Biomaterials. 1997;18(9):683-690. doi:10.1016/S0142-9612(96)00 183-4

18. Lebre F, Sridharan R, Sawkins MJ, Kelly DJ, O'Brien FJ, Lavelle EC. The shape and size of hydroxyapatite particles dictate inflammatory responses following implantation. Sci Rep. 2017;7 (1):2922. doi:10.1038/s41598-017-03086-0

19. Zhao $\mathrm{X}$, Heng $\mathrm{BC}$, Xiong $\mathrm{S}$, et al. In vitro assessment of cellular responses to rod-shaped hydroxyapatite nanoparticles of varying lengths and surface areas. Nanotoxicology. 2011;5(2):182-194. doi:10.3109/17435390.2010.503943

20. Zhao X, Ng S, Heng BC, et al. Cytotoxicity of hydroxyapatite nanoparticles is shape and cell dependent. Arch Toxicol. 2013;87 (6):1037-1052. doi:10.1007/s00204-012-0827-1

21. Tan YF, Lee YS, Seet L-F, Ng KW, Wong TT, Venkatraman S. Design and in vitro release study of siRNA loaded layer by layer nanoparticles with sustained gene silencing effect. Expert Opin Drug Deliv. 2018;15(10):937-949. doi:10.1080/17425247.2018.1518426

22. Hinderliter PM, Minard KR, Orr G, et al. ISDD: a computational model of particle sedimentation, diffusion and target cell dosimetry for in vitro toxicity studies. Part Fibre Toxicol. 2010;7(1):36. doi:10.1186/1743-8977-7-36

23. DeLoid G, Cohen JM, Darrah T, et al. Estimating the effective density of engineered nanomaterials for in vitro dosimetry. Nat Commun. 2014;5:3514. doi:10.1038/ncomms4514
24. He C, Hu Y, Yin L, Tang C, Yin C. Effects of particle size and surface charge on cellular uptake and biodistribution of polymeric nanoparticles. Biomaterials. 2010;31(13):3657-3666. doi:10.1016/j. biomaterials.2010.01.065

25. Gautam A, Rakshit M, Nguyen KT, et al. Understanding the implications of engineered nanoparticle induced autophagy in human epidermal keratinocytes in vitro. NanoImpact. 2019;15:100177. doi:10.1016/j.impact.2019.100177

26. Kim CS, Le NDB, Xing Y, et al. The role of surface functionality in nanoparticle exocytosis. Adv Healthc Mater. 2014;3(8):1200-1202. doi:10.1002/adhm.201400001

27. Wang Y, Wu Q, Sui K, et al. A quantitative study of exocytosis of titanium dioxide nanoparticles from neural stem cells. Nanoscale. 2013;5(11):4737-4743. doi:10.1039/c3nr00796k

28. Strobel C, Oehring H, Herrmann R, Förster M, Reller A, Hilger I. Fate of cerium dioxide nanoparticles in endothelial cells: exocytosis. J Nanopart Res. 2015;17(5):206. doi:10.1007/s11051-015-3007-4

29. Ignotz RA, Massague J. Transforming growth factor-beta stimulates the expression of fibronectin and collagen and their incorporation into the extracellular matrix. J Biol Chem. 1986;261(9):4337-4345.

30. Bettinger DA, Yager DR, Diegelmann RF, Cohen IK. The effect of TGF-beta on keloid fibroblast proliferation and collagen synthesis. Plast Reconstr Surg. 1996;98(5):827-833. doi:10.1097/00006534199610000-00012

31. Sottile J, Chandler J. Fibronectin matrix turnover occurs through a caveolin-1-dependent process. Mol Biol Cell. 2005;16(2):757-768. doi:10.1091/mbc.e04-08-0672

32. Fujimoto T, Kogo H, Nomura R, Une T. Isoforms of caveolin-1 and caveolar structure. J Cell Sci. 2000;113(Pt 19):3509-3517.

33. Xia T, Kovochich M, Liong M, Zink JI, Nel AE. Cationic polystyrene nanosphere toxicity depends on cell-specific endocytic and mitochondrial injury pathways. ACS Nano. 2008;2(1):85-96. doi:10.1021/nn700256c

34. Lencer WI, Hirst TR, Holmes RK. Membrane traffic and the cellular uptake of cholera toxin. Biochim Biophys Acta. 1999;1450 (3):177-190. doi:10.1016/S0167-4889(99)00070-1

35. Yousuf MA, Zhou X, Mukherjee S, et al. Caveolin-1 associated adenovirus entry into human corneal cells. PLoS One. 2013;8(10): e77462. doi:10.1371/journal.pone.0077462

36. Falcone S, Cocucci E, Podini P, Kirchhausen T, Clementi E, Meldolesi J. Macropinocytosis: regulated coordination of endocytic and exocytic membrane traffic events. J Cell Sci. 2006;119(Pt 22):4758-4769. doi:10.1242/jcs.03238

37. Swanson JA, Watts C. Macropinocytosis. Trends Cell Biol. 1995;5 (11):424-428. doi:10.1016/S0962-8924(00)89101-1

38. Behzadi S, Serpooshan V, Tao W, et al. Cellular uptake of nanoparticles: journey inside the cell. Chem Soc Rev. 2017;46 (14):4218-4244. doi:10.1039/C6CS00636A

39. Zhang Y, Hu L, Yu D, Gao C. Influence of silica particle internalization on adhesion and migration of human dermal fibroblasts. Biomaterials. 2010;31(32):8465-8474. doi:10.1016/j.biomaterials.2010.07.060

40. Hewlett LJ, Prescott AR, Watts C. The coated pit and macropinocytic pathways serve distinct endosome populations. J Cell Biol. 1994;124 (5):689-703. doi:10.1083/jcb.124.5.689

41. Perry DG, Daugherty GL, Martin WJ. Clathrin-coated pit-associated proteins are required for alveolar macrophage phagocytosis. J Immunol. 1999;162(1):380-386.

42. Parton RG, Joggerst B, Simons K. Regulated internalization of caveolae. J Cell Biol. 1994;127(5):1199-1215. doi:10.1083/jcb. 127.5.1199

43. Quignard S, Mosser G, Boissière M, Coradin T. Long-term fate of silica nanoparticles interacting with human dermal fibroblasts. Biomaterials. 2012;33(17):4431-4442. doi:10.1016/j.biomaterials. 2012.03.004

44. Walkey CD, Chan WC. Understanding and controlling the interaction of nanomaterials with proteins in a physiological environment. Chem Soc Rev. 2012;41(7):2780-2799. doi:10.1039/C1CS15233E 
45. Walczyk D, Bombelli FB, Monopoli MP, Lynch I, Dawson KA. What the cell "sees" in bionanoscience. J Am Chem Soc. 2010;132 (16):5761-5768. doi:10.1021/ja910675v

46. Luckett-Chastain LR, Gallucci RM. Interleukin (IL)-6 modulates transforming growth factor-beta expression in skin and dermal fibroblasts from IL-6-deficient mice. $B r \quad J$ Dermatol. 2009;161 (2):237-248. doi:10.1111/j.1365-2133.2009.09215.x

47. Gharaee-Kermani M, Denholm EM, Phan SH. Costimulation of fibroblast collagen and transforming growth factor betal gene expression by monocyte chemoattractant protein-1 via specific receptors. J Biol Chem. 1996;271(30):17779-17784. doi:10.1074/jbc.271. 30.17779

48. Yamamoto T, Eckes B, Krieg T. Effect of interleukin-10 on the gene expression of type I collagen, fibronectin, and decorin in human skin fibroblasts: differential regulation by transforming growth factor- $\beta$ and monocyte chemoattractant protein-1. Biochem Biophys Res Commun. 2001;281(1):200-205. doi:10.1006/bbrc.2001.4321

49. Bhogal RK, Bona CA. Regulatory effect of extracellular signal-regulated kinases (ERK) on type I collagen synthesis in human dermal fibroblasts stimulated by IL-4 and IL-13. Int Rev Immunol. 2008;27(6):472-496. doi:10.1080/08830180802430974
50. Yu Y, Zhu T, Li Y, et al. Repeated intravenous administration of silica nanoparticles induces pulmonary inflammation and collagen accumulation via JAK2/STAT3 and TGF- $\beta / \mathrm{Smad} 3$ pathways in vivo. Int J Nanomedicine. 2019;14:7237-7247. doi:10.2147/IJN.S209458

51. Inagaki Y, Truter S, Tanaka S, Di Liberto M, Ramirez F. Overlapping pathways mediate the opposing actions of tumor necrosis factor-alpha and transforming growth factor-beta on alpha 2(I) collagen gene transcription. J Biol Chem. 1995;270(7):3353-3358. doi:10.1074/ jbc.270.7.3353

52. Inagaki Y, Truter S, Ramirez F. Transforming growth factor-beta stimulates alpha 2(I) collagen gene expression through a cis-acting element that contains an Sp1-binding site. J Biol Chem. 1994;269 (20):14828-14834.

53. Kouba DJ, Chung K-Y, Nishiyama T, et al. Nuclear factor- $\kappa$ B mediates TNF- $\alpha$ inhibitory effect on $\alpha 2(\mathrm{I})$ collagen (COL1A2) gene transcription in human dermal fibroblasts. J Immunol. 1999;162 (7):4226-4234.
International Journal of Nanomedicine

\section{Publish your work in this journal}

The International Journal of Nanomedicine is an international, peerreviewed journal focusing on the application of nanotechnology in diagnostics, therapeutics, and drug delivery systems throughout the biomedical field. This journal is indexed on PubMed Central, MedLine, CAS, SciSearch ${ }^{\mathbb{R}}$, Current Contents ${ }^{\mathbb{R}} /$ Clinical Medicine, $^{-}$

\section{Dovepress}

Journal Citation Reports/Science Edition, EMBase, Scopus and the Elsevier Bibliographic databases. The manuscript management system is completely online and includes a very quick and fair peer-review system, which is all easy to use. Visit http://www.dovepress.com/ testimonials.php to read real quotes from published authors. 